\title{
Family Physician Participation in Quality Improvement
}

\author{
Lars E. Peterson, MD, PhD, Carlos Roberto Jaén, MD, PhD, and \\ Robert L. Phillips, MD, MSPH
}

More than one-third of family physicians reported participating in a quality improvement $(Q I)$ activity in the past year. Continuous $Q I$ is vital to improving personal and population health outcomes and reducing costs. Support for QI activities, their evaluation, and the dissemination of successful efforts are sorely needed. (J Am Board Fam Med 2013;26:626-627.)

Measurement and reporting of the quality of care physicians deliver is becoming increasingly important. ${ }^{1,2}$ Payment bonuses or penalties often are tied to the quality of care delivered. Family physicians participating in the American Board of Family Medicine's (ABFM) Maintenance of Certification for Family Physicians (MC-FP) are required to complete a quality improvement (QI) project every 3 years, but they can meet this requirement through other avenues or can perform QI more often. While training in QI is associated with performing QI in practice, ${ }^{3}$ the prevalence of QI activities among family physicians remains unknown.

We used data from a convenience sample of all family physicians that accessed their physician portfolio on the ABFM website during a 2-week period in September and October 2011. These

This article was externally peer reviewed.

Submitted 21 November 2012; revised 14 May 2013; accepted 23 May 2013.

From the American Board of Family Medicine, Lexington, KY (LEP, RLP); and the Departments of Family and Community Medicine and Epidemiology and Biostatistics, University of Texas Health Science Center at San Antonio, Research to Advance Community Health (ReACH) Center, San Antonio, TX (CRJ).

Funding: none.

Conflict of interest: none declared.

Corresponding author: Lars E. Peterson, MD, PhD, American Board of Family Medicine, 1648 McGrathiana Parkway, Suite 550, Lexington, KY 40511-1247 (E-mail: lpeterson@ theabfm.org).

\section{See Related Commentary on Page 620.}

physicians completed a brief survey that included the question: "In the last year, have you personally participated in a Quality Improvement Project or PDSA [Plan Do Study Act]?” We used this question to represent participation in a QI activity.

During this 2-week period, 5818 family physicians residing in the 50 United States completed the survey (Table 1). The respondents were slightly younger and more likely to be female, be board certified, and to have completed more MC-FP activities than other physicians in the ABFM database. Of the respondents, $38 \%$ reported participating in a QI activity in the past year. Part 4 of MC-FP can be met by performing a QI activity, so it is not surprising that physicians who reported QI participation completed more MC-FP activities,

Table 1. Family Physicians Participation in a Quality Improvement (QI) Activity in the Past Year

\begin{tabular}{lcc}
\hline & $\begin{array}{c}\text { QI Activity in } \\
\text { Past Year } \\
(\mathrm{n}=2231 ; \\
38.4 \%)\end{array}$ & $\begin{array}{c}\text { No QI Activity } \\
\text { in Past Year } \\
(\mathrm{n}=3587 ; \\
61.7 \%)\end{array}$ \\
\hline Mean age, years (SD) & $48.2(9.2)$ & $47.8(9.7)$ \\
Male sex & 60.4 & $56.0^{*}$ \\
Medical degree & 90.6 & 91.0 \\
Currently certified & 96.6 & 96.4 \\
Mean MC-FP modules & $4.1(2.5)$ & $3.6(2.5)^{*}$ \\
completed (SD) & & $36.0^{*}$ \\
Any MC-FP Part 4 module & 48.3 & 80.4 \\
Urban & 80.6 & \\
\hline
\end{tabular}

Data are percentages unless otherwise indicated.

${ }^{*} P<0.01$.

MC-FP, Maintenance of Certification for Family Physicians; $\mathrm{SD}$, standard deviation. 
and specifically were more likely to have completed a Part 4 module, than those who did not participate in a QI activity. There was no difference in QI participation between rural and urban physicians or by degree type.

In a small convenience sample, $38 \%$ of family physicians reported some involvement in QI in the past year. Since we assessed only QI participation in the past year, overall involvement in QI projects may be higher than reported here. Continuously improving the quality of health care through QI activities is becoming increasingly important since new health care delivery and payment models are tied to the quality of care provided. Through Part 4 of MC-FP, physicians can increase their knowledge and use of QI; however, further practice redesign, with concomitant increases in payments to support these changes, is needed to advance the triple aim of better health, higher quality, and lower costs. ${ }^{4}$

\section{References}

1. Rosenthal MB, Fernandopulle R, Song HR, Landon B. Paying for quality: providers' incentives for quality improvement. Health Aff (Millwood) 2004; 23:127-41.

2. Mayes R. Moving (realistically) from volume-based to value-based health care payment in the USA: starting with Medicare payment policy. J Health Serv Res Policy 2011;16:249-51.

3. Diaz VA, Carek PJ, Johnson SP. Impact of quality improvement training during residency on current practice. Fam Med 2012;44:569-73.

4. Berwick DM, Nolan TW, Whittington J. The triple aim: care, health and cost. Health Aff (Millwood) 2008;27:759-69. 